\title{
$\angle$ Research Square \\ Prevalence of neonatal near miss and associated factors in Nepal: a cross-sectional study
}

\section{Sushma Rajbanshi}

Universiti Sains Malaysia - Kampus Kesihatan

Norhayati Mohd Noor ( $\sim$ hayatikk@usm.my)

Universiti Sains Malaysia - Kampus Kesihatan https://orcid.org/0000-0002-1884-4020

Nik Hazlina Nik Hussain

Universiti Sains Malaysia - Kampus Kesihatan

\section{Research article}

Keywords: neonatal near miss, neonatal morbidity, severe maternal morbidity, cross-sectional study, Nepal

Posted Date: January 22nd, 2021

DOl: https://doi.org/10.21203/rs.3.rs-42794/v3

License: (c) (i) This work is licensed under a Creative Commons Attribution 4.0 International License. Read Full License 


\section{Abstract}

Background: Unlike the infant mortality rate, the rate of neonatal mortality has not significantly declined and remains a major health challenge in the low- and middle-income countries. There is an urgent need to focus on newborn care, especially during the first 24 hours after birth and the early neonatal period. Neonatal near miss (NNM) is an emerging concept similar to that of maternal near miss. NNM events occur three to eight times more often than neonatal deaths. The objective of this study was to establish the prevalence of NNM and identify its associated factors.

Methods: A hospital-based cross-sectional study was conducted in Koshi Hospital, Morang district, Nepal. Neonates and their mothers of unspecified maternal age and number of gestational weeks were enrolled. The key inclusion criterion was the pragmatic and management markers of NNM, and admission of newborn infants to the neonatal intensive care unit (NICU) in Koshi Hospital. Non-Nepali citizens were excluded. Consecutive sampling was used until the required sample size of 1,000 newborn infants was reached. Simple and multiple logistic regression was performed using SPSS ${ }^{\circledR}$ version 24.0.

Results: One thousand respondents were recruited. Prevalence of NNM was 79 per 1,000 live births. Severe maternal morbidity (adjusted odds ratio (aOR) 4.52; 95\% confidence interval (Cl): 2.07-9.84), no education (aOR 2.16; 95\% Cl 1.12-4.14), multiparity (aOR 0.52; 95\% $\mathrm{Cl} 0.32-0.86$ ), and caesarean section (aOR 0.44: 95\% $\mathrm{Cl} 0.19-0.99$ ) were associated with NNM.

Conclusions: Prevalence of NNM in Nepal was 7.9\%. Mothers' obstetric factors, maternal complications and education were associated with NNM. Women in referral hospitals should have safer access to caesarean section and be prepared for NICU intervention to save mothers and their newborns.

\section{Background}

The rate of paediatric mortality has long been considered an important indicator of social development, economic prosperity and healthcare quality. Globally, a $51 \%$ decline in neonatal mortality was recorded between 1990 and 2017; however, the decline in neonatal mortality has been slower than that of postneonatal under-five mortality (1). At country level, annual neonatal mortality rates range from 0.9 to 44.2 deaths per 1,000 live births (1). South Asia had 25 neonatal deaths per 1,000 live births in 2018 (2), and is a hub of the highest number of neonatal deaths along with sub-Saharan Africa (1); a child born in this region is 10 times more likely to die in the first month of life than a child born in a high-income country (2). The objective of Sustainable Development Goal (SDG) 3 and that of the global Every Newborn Action Plan is to reduce neonatal mortality to 10 or less per 1,000 live births by 2030 (3).

The neonatal mortality rate in Nepal was 21 per 1,000 live births in 2016; of the total neonatal deaths, about four-fifths (79\%) were early neonatal deaths; and $57 \%$ of all births were institutional births (4). There are large variations in neonatal mortality within provinces from 15 to 71 per 1,000 live births. Nepal needs to reduce the rate of neonatal mortality by half in the next 10 years if it is to achieve SDG target 3.2. Thus, accelerated efforts are needed to address interprovincial disparities with regard to neonatal 
mortality rates. Neonatal near miss (NNM) is a novel concept that has recently emerged and is similar to maternal near miss (MNM) concept. It provides vital information required for an evaluation of the quality of care provided in hospital and explores opportunities to improve the performance of healthcare providers (5). Near-miss events occur three to eight times more often than neonatal deaths $(6,7)$. Thus, NNM evaluations can provide abundant evidence of the causal pathways responsible for neonatal deaths (8).

Conceptualization of the term "NNM" in 2009, similar to "MNM," was proposed by Avenant (9). That same year, Pileggi et al. established pragmatic NNM criteria using the 2005 WHO Global Survey data (10). Initial definition of pragmatic markers included very low birth weight (i.e., $<1,500 \mathrm{~g}$ ), gestational age at birth ( $<30$ weeks), or Apgar score ( $<7$ at five minutes), surviving seven days after birth (10).

Pileggi-Castro et al. re-evaluated the NNM definition using WHO Global Survey data and validated the revised definition using the WHO Multi-Country Survey on Maternal and Newborn Health data (10-12). NNM refers to "neonates that nearly died but survived severe complications at birth or during the neonatal period" $(10,12)$. The recommended pragmatic criteria were birthweight below $1,750 \mathrm{~g}$, gestational age < 33 weeks or Apgar score $<7$ at five minutes in newborn infants who go on to survive for seven days. Whereas for diagnostic accuracy, management markers from this definition included the use of therapeutic intravenous antibiotics, nasal continuous positive airway pressure, intubation, phototherapy within the first 24 hours, cardiopulmonary resuscitation, vasoactive drugs, anticonvulsants, surfactant administration, blood products, steroids to treat refractory hypoglycemia and surgery in early neonatal life (13). The pragmatic criteria and management markers developed by Pileggi-Castro et al. were shown to have a sensitivity of $93 \%$ and specificity of $97 \%(13)$.

There is no uniform definition of NNM to this date although a vast number of NNM studies are available. Systematic reviews on NNM, conducted in 2015 and 2017, had recommended to develop a standard definition for NNM $(14,15)$. Worldwide prevalence of NNM ranged from 39.2 to 131 per 1,000 live births in 2014 and $2018(16,17)$. A population-based study conducted in Nepal applied community-appropriate NNM criteria adapted from Pileggi et al.(10) and adjusted to the local context, demonstrated a prevalence of 22 per 1,000 live births (18). NNM was shown to be caused by birth asphyxia (70\%), very low birth weight (17\%), neonatal sepsis (10\%) and prematurity (3\%) (18).

The NNM definition proposed by Pileggi-Castro et al. is used in this study. Researchers assessing NNM in South Asia, have applied pragmatic criteria only $(19,20)$. Thus, the current study is the first to use a combination of pragmatic and management criteria in Nepal to establish the prevalence of NNM and identify associated factors. In this study, NNM referred to "an infant who nearly died but survived a severe complication that occurred during pregnancy, birth or within seven days of extrauterine life" (13). Shifting the focus from neonatal mortality towards NNM and its associated factors can be useful information for policymakers for improvement of care.

\section{Methods}


This cross-sectional study was conducted on 1000 newborn infants and their mothers admitted to the postnatal ward in Koshi Hospital, Morang district, Nepal. Morang district was chosen based on its high population density and diverse ethnicity. It is a referral hospital for the eastern part of Nepal and has a neonatal intensive care unit (NICU). Koshi Hospital is located in Biratnagar city of Morang district, and is the second-most densely populated city in Nepal with a population of 1,058,985 and an average of 27,833 annual pregnancies (21). The hospital has 35 beds in postnatal ward and manages approximately 9,000 annual births. The NICU contains six beds and admits approximately 45 neonates per month.

Mothers of any age with neonates born after any gestational age who survived for seven days were included in this study. Non-Nepali citizens and non-Morang residents were excluded. Consecutive sampling was applied. Sample size was calculated based on the prevalence of NNM using a single proportion formula. With NNM prevalence of $2.2 \%$ (18), a precision of 0.01 and a $20 \%$ non-response rate, the calculated sample size was determined to be 1,000 newborn infants.

The research tool comprised of maternal and neonatal hospital records and socio-demographic information. Two research assistants, who were recent nursing undergraduates, collected the data daily. The hospital's records on obstetric history, pregnancy complications, and data on the newborns were extracted into a case report form on the day of discharge of the mother. Newborns in NICU were followed up daily and their information updated after discharge. Socio-demographic information was obtained from the mothers using face-to-face interview.

Data were entered and analysed using IBM SPSS ${ }^{\circledR}$ Statistics 24.0. Frequencies and percentages were calculated for categorical variables; mean, median, standard deviation and interquartile range were determined for the numerical variables. Simple and multiple logistic regression was used to assess associated factors. Clinically significant variables in simple logistic regression analysis and those with $p$ value $<0.3$ were included in the multiple logistic regression analysis. Adjusted odds ratio (aOR), corresponding $95 \%$ confidence interval $(\mathrm{Cl})$, and $p$-value $<0.05$ were calculated and considered statistically significant.

Outcome variable was NNM status (13). Independent variables were ethnicity, religion, wealth index, place of residence, maternal and paternal education, maternal and paternal occupation, paternal smoking habit, maternal age, age of marriage, duration of marriage, parity, number of antenatal care visits (ANC), selfreported pre-pregnancy body mass index, mode of birth, maternal haemorrhagic disorders, maternal hypertensive disorders, other maternal systemic disorders, maternal severe management indicators, severe maternal morbidity (SMM) and sex of the newborn infants.

\section{Results}

One thousand newborns and their mothers were recruited for the study between November 2019 and March 2020. There were 18 perinatal deaths (17 stillbirths and one early neonatal death) during the study period. There were 10 multiple births, and these were treated as a single birth. Of these, four were NNM cases. 
Prevalence of NNM was 79 per 1,000 live births in Koshi Hospital (Table 1). Table 1 shows pragmatic ( $n=$ $65)$ and management markers $(n=27)$ used to evaluate NNM. NNM markers were found overlapping in newborns. The most frequently encountered pragmatic criterium was an Apgar score $<7$ five minutes after birth $(41 / 65 ; 63.1 \%)$ followed by the birth weight $<1,750 \mathrm{~g}(20 / 65 ; 30.7 \%)$. All three pragmatic criteria applied to only one newborn infant. Of the neonates with pragmatic markers $(35 / 65 ; 53.9 \%)$ required NICU admission, and of those evaluated using management markers who were admitted to NICU (24/27; $88.9 \%)$ had at least one pragmatic marker criterium.

Newborns referred for NICU admissions were 44, but, 17 of these newborns were admitted to nearby private hospitals; therefore, only 27 newborns hospital records could be accessed from the Koshi hospital as shown in Table 1. The majority of newborn infants in NICU were treated with therapeutic antibiotics $(25 / 27 ; 92.6 \%)$ and nasal continuous positive airway pressure $(19 / 27 ; 70.3 \%)$.

Table 1 Pragmatic and management criteria of NNM in Koshi Hospital

\begin{tabular}{lrl}
\hline NNM characteristics & $\mathrm{n}$ & $(\%)$ \\
\hline Pragmatic criteria & & \\
APGAR Score $<7$ in 5 minutes & 41 & $(63.1)$ \\
Birth weight $<1750 \mathrm{~g}$ & 20 & $(30.7)$ \\
Gestation age $<33$ weeks & 11 & $(16.9)$ \\
Any pragmatic marker of severity & 65 & $(100.0)$ \\
Management criteria & & \\
Use of therapeutic antibiotics & $25 \quad(92.6)$ \\
& $19(70.3)$ \\
Nasal continuous positive airway pressure & $11(40.7)$ \\
Cardiopulmonary resuscitation & 6 (22.2) \\
Use of phototherapy in the first 24 hours & $3(11.1)$ \\
Any intubation (anytime within the first week) & $2(7.4)$ \\
Use of anticonvulsants & 1 & $(3.7)$ \\
Use of steroids to treat refractory hypoglycemia & 0 & $(0)$ \\
Surfactant administration & 0 & $(0)$ \\
Use of a vasoactive drug & 0 & $(0)$ \\
Use of any blood products & 0 & $(0)$ \\
Any surgery & 27 & $(100.0)$ \\
Admission to NICU with any management marker of severity & $79(7.9)$ \\
\hline Overall NNM & \\
\hline
\end{tabular}

*APGAR Score: Appearance, Pulse, Grimace, Activity, and Respiration

** 79 newborns with NNM had 92 NNM criteria

Socio-demographic and maternal characteristics with and without NNM are depicted in Table 2. The proportion of adolescent mothers (<20 years) was higher for NNM $(17 / 79 ; 21.5 \%)$ as compared to those without NNM $(93 / 921 ; 10.1 \%)$.

Table 2 Socio-demographic and maternal characteristics based on NNM status 


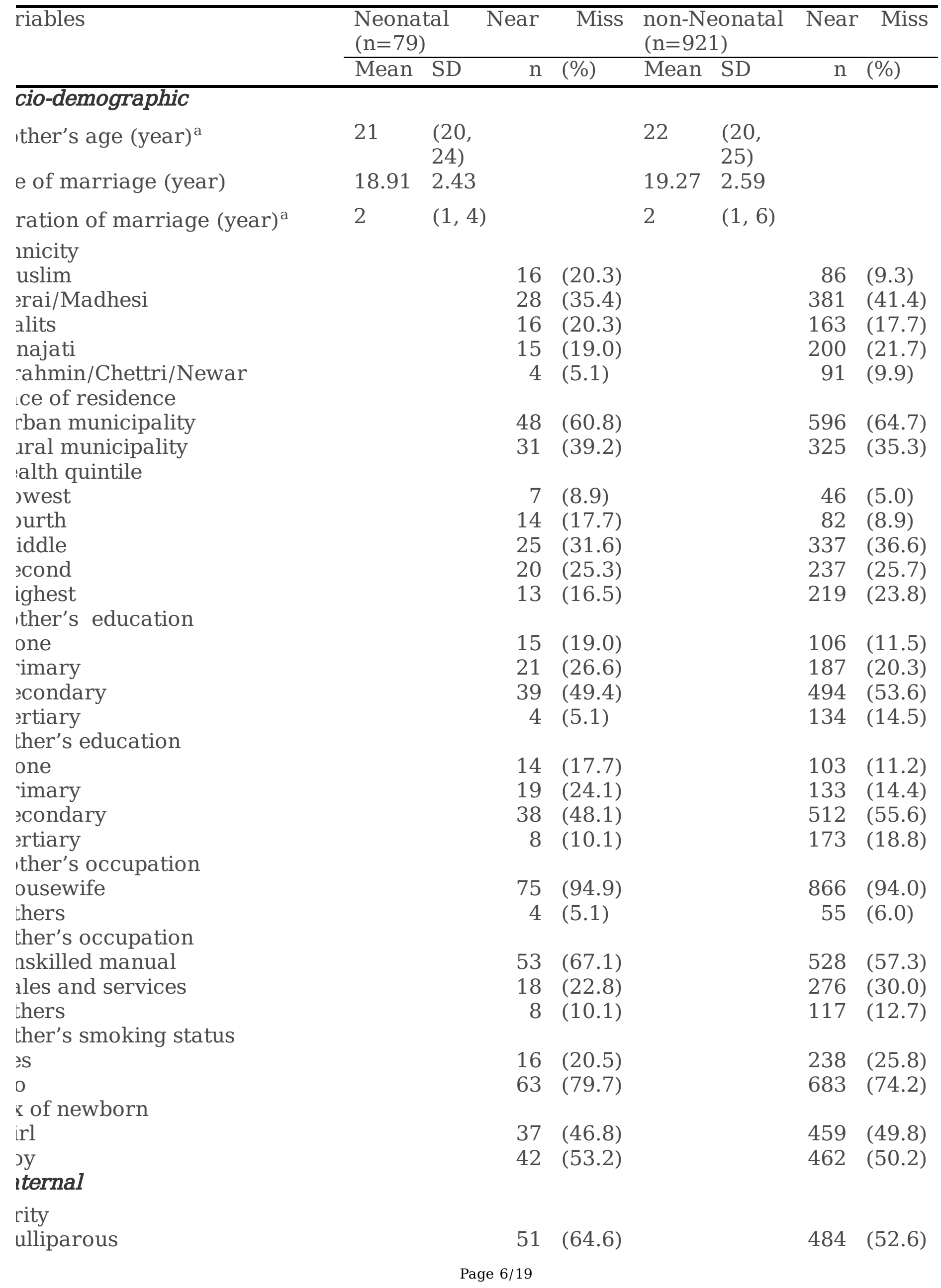


ultiparous

ide of birth

aginal birth

zesarean section

s-pregnancy $\mathrm{BMI}^{\mathrm{b}}$

ormal

nderweight

verweight and obese

mber of $\mathrm{ANC}^{\mathrm{C}}$

3 visits

4 visits

$\left[\mathrm{M}^{\mathrm{d}}\right.$

'esent

jsent

ternal haemorrhagic

orders

resent

गsent

ternal hypertensive disorders

esent

jsent

ternal severe management

icators

esent

jsent
$28 \quad(35.4)$

$72 \quad(91.1)$

7 (8.9)

59 (74.7)

15 (19.0)

5 (6.3)

$35 \quad(44.3)$

44 (55.7)

$10 \quad(12.7)$

69 (87.3)

$2 \quad(2.5)$

77 (97.5)

$6 \quad(7.6)$

73 (92.4)

$437 \quad(47.4)$

$762 \quad$ (82.7)

159 (17.3)

$690 \quad$ (74.9)

$160 \quad(17.4)$

71 (7.7)

$583 \quad(63.3)$

338 (36.7)

35 (3.8)

$886 \quad(96.2)$

$16 \quad(1.7)$

905 (98.3)

12 (1.3)

909 (98.7)

2 (2.5)

$16 \quad(1.7)$

$77 \quad(97.5)$

a Expressed as median (interquartile range). Skewed to the right

$\mathrm{b}_{\mathrm{BMI}}=$ body mass index, ${ }^{\mathrm{c}} \mathrm{ANC}=$ antenatal care, ${ }^{\mathrm{d}} \mathrm{SMM}=$ severe maternal morbidity

The 20 independent variables associated with NNM were evaluated using simple logistic regression analysis (Table 3).

Table 3 Associated factors for neonatal NNM using simple logistic regression 


\begin{tabular}{|c|c|c|c|c|}
\hline Variables & $\begin{array}{r}\text { Crude } \\
\text { OR }\end{array}$ & $(95 \% \mathrm{CI})$ & $\begin{array}{c}\text { Wald } \\
\text { stat }^{\mathrm{a}}(\mathrm{df})^{\mathrm{b}}\end{array}$ & $\begin{array}{c}\mathrm{P} \\
\text { value }\end{array}$ \\
\hline Mother's age & 0.93 & $(0.87,0.99)$ & $4.23(1)$ & 0.040 \\
\hline Age of marriage & 0.94 & $(0.86,1.04)$ & $1.42(1)$ & 0.232 \\
\hline Duration of marriage & 0.95 & $(0.89,1.02)$ & $1.75(1)$ & 0.186 \\
\hline \multicolumn{5}{|l|}{ Ethnicity } \\
\hline $\begin{array}{l}\text { Muslim } \\
\text { Terai/Madhesi }\end{array}$ & $\begin{array}{r}2.53 \\
1\end{array}$ & $(1.31,4.88)$ & $0.01(1)$ & 0.006 \\
\hline Dalits & 1.33 & $(0.70,2.53)$ & $0.78(1)$ & 0.376 \\
\hline Janajati & 1.02 & $(0.53,1.95)$ & $0.00(1)$ & 0.951 \\
\hline Brahmin/Chettri/Newar & 0.59 & $(0.20,1.75)$ & $0.88(1)$ & 0.376 \\
\hline \multicolumn{5}{|l|}{ Place of residence } \\
\hline Urban municipality & 1 & & & \\
\hline Rural municipality & 0.84 & $(0.52,1.35)$ & $0.49(1)$ & 0.482 \\
\hline \multicolumn{5}{|l|}{ Wealth quintile } \\
\hline Lowest & 2.05 & $(0.84,5.01)$ & $2.48(1)$ & 0.115 \\
\hline Fourth & 2.30 & $(1.14,4.62)$ & $5.49(1)$ & 0.019 \\
\hline Middle & 1 & & & \\
\hline Second & 1.14 & $(0.62,2.10)$ & $1.71(1)$ & 0.679 \\
\hline Highest & 0.80 & $(0.40,1.60)$ & $0.40(1)$ & 0.527 \\
\hline \multicolumn{5}{|l|}{ Mother's education } \\
\hline None & 1.79 & $(0.95,3.37)$ & $3.28(1)$ & 0.070 \\
\hline Primary & 1.42 & $(0.81,2.48)$ & $1.54(1)$ & 0.215 \\
\hline Secondary & 1 & & & \\
\hline Tertiary & 0.38 & $(0.13,1.08)$ & $3.32(1)$ & 0.378 \\
\hline \multicolumn{5}{|l|}{ Father's education } \\
\hline None & 1.83 & $(0.96,3.50)$ & $3.34(1)$ & 0.067 \\
\hline Primary & 1.92 & $(1.07,3.45)$ & $4.85(1)$ & 0.028 \\
\hline Secondary & 1 & & & \\
\hline Tertiary & 0.62 & $(0.28,1.36)$ & $1.41(1)$ & 0.236 \\
\hline \multicolumn{5}{|l|}{ Mother's occupation } \\
\hline Housewife & 1 & & & \\
\hline Others & 0.84 & $(0.29,2.38)$ & $0.11(1)$ & 0.743 \\
\hline \multicolumn{5}{|l|}{ Father's occupation } \\
\hline Unskilled manual & 1 & & & \\
\hline Sales and services & 0.65 & $(0.37,1.13)$ & $2.32(1)$ & 0.127 \\
\hline Others & 0.68 & $(0.31,1.47)$ & $0.95(1)$ & 0.328 \\
\hline \multicolumn{5}{|l|}{ Father's smoking status } \\
\hline No & 1 & & & \\
\hline Yes & 0.73 & $(0.41,1.28)$ & $1.19(1)$ & 0.275 \\
\hline \multicolumn{5}{|l|}{ Sex of newborn } \\
\hline Boy & 1 & & & \\
\hline Girl & 0.89 & $(0.56,1.40)$ & $0.26(1)$ & 0.609 \\
\hline \multicolumn{5}{|l|}{ Mode of birth } \\
\hline Vaginal birth & 1 & & & \\
\hline Caesarean section & 0.47 & $(0.21,1.03)$ & $3.55(1)$ & 0.060 \\
\hline \multicolumn{5}{|l|}{ Pre-pregnancy BMI } \\
\hline Normal & 1 & & & \\
\hline Underweight & 1.09 & $(0.60,1.98)$ & $0.09(1)$ & 0.761 \\
\hline
\end{tabular}




\begin{tabular}{|c|c|c|c|c|}
\hline Overweight & 0.82 & $(0.32,2.12)$ & $0.16(1)$ & 0.687 \\
\hline \multicolumn{5}{|l|}{ Parity } \\
\hline Nulliparous & 1 & & & \\
\hline Multiparous & 0.61 & $(0.38,0.98)$ & 4.14 & 0.042 \\
\hline \multicolumn{5}{|l|}{ Number of ANC } \\
\hline$\leq 3$ visits & 1 & & & \\
\hline$\geq 4$ visits & 0.73 & $(0.45,1.16)$ & $1.78(1)$ & 0.181 \\
\hline \multicolumn{5}{|l|}{ SMM } \\
\hline Absent & 1 & & & \\
\hline Present & 3.67 & $(1.74,7.72)$ & $11.72(1)$ & 0.001 \\
\hline Maternal haemorrhagic disorders & 1 & & & \\
\hline Absent & 1.47 & $(0.33,6.51)$ & $0.26(1)$ & 0.612 \\
\hline Present & & & & \\
\hline \multicolumn{5}{|l|}{ Maternal hypertensive disorders } \\
\hline Absent & 1 & & & \\
\hline Present & 6.23 & $\begin{array}{l}(2.27, \\
17.07)\end{array}$ & $12.63(1)$ & 0.000 \\
\hline \multicolumn{5}{|l|}{$\begin{array}{l}\text { Maternal severe management } \\
\text { indicators }\end{array}$} \\
\hline Absent & 1 & & & \\
\hline Present & 1.47 & $(0.33,6.51)$ & $0.26(1)$ & 0.612 \\
\hline
\end{tabular}

Note: $\mathrm{BMI}=$ body mass index, $\mathrm{ANC}=$ antenatal care, $\mathrm{SMM}=$ severe maternal morbidity

${ }^{\mathrm{a}}$ Wald statistics

$\mathrm{b}$ Degree of freedom

Among 20 independent variables, ethnicity, wealth quintile, mother's education, father's education, father's occupation, father's smoking habit, mother's age, age of marriage, duration of marriage, parity, mode of birth, number of ANC visits, maternal hypertensive disorders, and SMM were identified as associated variables with $P<0.3$. They were included in multiple logistic regression analysis.

Mother's education, parity, mode of birth and SMM were found to be significantly associated with NNM. Mothers without education (aOR: $2.16,95 \% \mathrm{Cl}$ : 1.13-4.14) were 2.16 times the odds of experiencing NNM than those with secondary education. Multiparous mothers (aOR: $0.52 .95 \% \mathrm{Cl}: 0.39-0.86)$ were less likely to encounter NNM than nulliparous mothers. Newborns born by caesarean section were less likely to be NNM cases (aOR: $0.44,95 \% \mathrm{Cl}$ : 0.19-0.99) compared to neonates born vaginally. Similarly, mothers with SMM were at higher odds of giving birth to a NNM infant (aOR: 4.52, 95\% Cl: 2.07-9.84) than those without NNM (Table 4).

Table 4 Associated factors for NNM using multiple logistic regression analysis 


\begin{tabular}{lllc}
\hline Variables & aOR & $95 \%$ CI & Wald stat $^{\mathrm{a}}(\mathrm{df})^{\mathrm{b}}$ \\
\hline Education of women & & & \\
$\quad$ None & 2.16 & $(1.13,4.14)$ & $5.40(1)$ \\
Primary & 1.43 & $(0.81,2.53)$ & $1.57(1)$ \\
$\quad$ Secondary & 1 & & \\
Tertiary & 0.38 & $(0.13,1.10)$ & $3.18(1)$ \\
Parity & & & \\
$\quad$ Nulliparous & 1 & & $6.53(1)$ \\
$\quad$ Multiparous & 0.52 & $(0.32,0.86)$ & \\
Mode of birth & & & \\
$\quad$ Vaginal birth & 1 & & \\
$\quad$ Caesarean section & 0.44 & $(0.19,0.99)$ & \\
SMM status & & & $14.43(1)$ \\
$\quad$ Absent & 1 & & \\
Present & 4.52 & $(2.07,9.84))$ & \\
\hline
\end{tabular}

Note: SMM = severe maternal morbidity

a Wald statistics

b Degree of freedom

Note. No significant interaction; no multicollinearity problems model assumptions met; no influential outliers

\section{Discussion}

The prevalence of NNM was determined to be 79 per 1,000 live births in Koshi Hospital, Nepal, using a combination of pragmatic and management criteria. Multiparity and caesarean section decreased the likelihood of NNM. SMM and mothers with no education were found to increase the risk of NNM.

Consensus is lacking regarding a standardized period in which NNM is agreed to occur across countries, which makes it difficult to compare NNM-rates between studies. Some studies have used a near-miss period of $0-6$ days $(7,10,13,22,23)$, while others have utilized $0-27$ days $(15,17,19,20,24,25)$. Kale et al. recommend extending extrauterine life from seven to 28 days to increase sensitivity of near miss criteria. A decrease in sensitivity was, however, found when it was applied to 0-364 days (26). In the current study, a period of seven days was used because four-fifths of neonatal deaths still occur within the first week of life, with one quarter taking place in the first 24 hours (27). Besides, the chance of information bias increases if NNM information is obtained from parents in the community after hospital discharge.

The prevalence of NNM in this study, when compared, was within the range of previous studies of 45.1 to 72.5 per 1,000 live births, that used the same definition proposed by Pileggi-Castro, et al. $(7,13)$. A population-based study in Nepal reported NNM prevalence of 22 per 1,000 live births, which is lower than in the current hospital-based study (18). Possible reasons may be due to differences in used NNM definition and criteria as well as the study settings $(15,20)$. 
Prevalence of NNM was 87.6 per 1,000 live births in two studies from India, using only pragmatic criteria $(19,20)$. This is higher than the 65 per 1,000 live births (pragmatic criteria only) in our study. A possible explanation is that a survival period of 28 days was used in India; hence, sensitivity increased owing to the more extended survival period.

Multiparity decreased the likelihood of NNM in the current study, similar to other studies $(17,25)$. Studies from southern and northern Ethiopia, however, reported that multiparity was a risk factor for NNM $(28,29)$. A recent prospective cohort study in Ethiopia reported that grand multiparity was a risk factor for perinatal mortality among women with MNM (30).

Both nulliparous and grand-multiparous mothers were at high risk of developing complications during birth $(31,32)$, which places neonates at risk of adverse outcomes $(22,33,34)$. Nulliparity among mothers $\geq 35$ years was a risk factor for adverse perinatal outcomes $(35,36)$. Neonates born to advanced aged nulliparous women had a higher likelihood of admission to NICU (36-38). In this study, however, the proportion of women aged $\geq 35$ years and with $>4$ children were small, preventing to draw further conclusions.

Literature reviews suggest that a nulliparous women are at increased risk of hypertension and lack experience in childbirth $(39,40)$. This elucidates the likelihood of NNM affecting nulliparous women (22, 34). Prior studies have shown that first-born infants are at higher risk of neonatal mortality than secondor third-born infants $(39,41)$. In some studies, however, parity was not shown to be associated with neonatal mortality (42).

Elsewhere, a high chance of NNM affected women undergoing caesarean section $(25,28,43-45)$. In recent studies in India and Ethiopia, although NNM occurred more frequently in women who underwent caesarean birth, a direct association could not be established $(7,20)$. Contrary to these studies, in our study caesarean section was protective against NNM. In support of this finding, caesarean section reduced neonatal mortality in preterm births in the United States (46). A study in the Gambia found that in women with SAMM risks of stillbirth among vaginal birth increased four-fold compared to caesarean birth (47).

WHO recommends caesarean section only when medically necessary and recommends an upper population limit of $15 \%$ (48). In Koshi Hospital, the percentage of caesarean birth was $17 \%$, which is higher than $12 \%$ in public hospitals in Nepal (4). The proportion of caesarean sections performed in mothers with SMM was two times higher than in mothers without SMM (31\% versus 16\%). Previous literature shows SMM to be significantly associated with higher percentages of caesarean section and higher numbers of preterm birth occurred in mothers with SMM than without $(49,50)$. An increase in fetal deaths and higher numbers of babies admitted to NICU for $\geq 7$ days was found together with increased in numbers of caesarean birth (51). A systematic review and meta-analysis showed that maternal and perinatal outcomes were often linked (52). Mothers at high risk of maternal complications often gave birth by second stage caesarean sections to babies with low Apgar scores at 5 min. They were more likely to be admitted to NICU than after caesarean section during the first stage of labor (52). 
Risks of intraoperative complications and haemorrhage following caesarean birth are high in low and middle income countries (52). Timely intervention can prevent adverse neonatal outcome among women with SAMM $(52,53)$. Caesarean section could be a confounder if an operational procedure is performed only among fetus with a greater likelihood of being born alive (54). However, overall, there is a lack of consensus in the literature that neonatal mortality and morbidity are higher in infants delivered by caesarean section $(52,55-58)$.

In the current study, maternal secondary education decreased the likelihood of NNM. Prior studies have not established a significant association between NNM and maternal education $(7,17,20,28,43)$. A universal association, however, between maternal education and neonatal mortality, especially in low income countries, has been demonstrated and supports current study's findings [39, 59, 61, 62]. In addition, educated mothers more likely have a higher socio-economic status, have better knowledge of healthy behaviours, have a more informed approach to self-care, make better health-related choices and utilize healthcare appropriately $(33,59)$.

The current study found an association between SMM and NNM, consistent with a study in Ethiopia (7), but contradictory to one in Brazil (60). Very few studies, however, have explored the relationship between MNM and NNM. One study showed a strong association (OR 17.15; 95\% $\mathrm{Cl} 1.85-159.12$ ), whereas others have not demonstrated a significant association between MNM and NNM $(17,45)$. Mixed associations existed between haemorrhage and hypertensive disorders during pregnancy and NNM in southern Ethiopia (28) and Brazil (25). In support of the current study, an association between MNM and higher rates of adverse perinatal outcome was found $(47,54,61,62)$. Tura et al. claim that adverse perinatal outcomes among SAMM women is self-evident given the fact that SAMM are identified using severe clinical criteria along with organ disfunction (30).

Among women with SAMM, also NNM is higher $(22,63-65)$. A considerable number of newborn infants with severe hypoxia, low birth weight and neonatal asphyxia were born to women with MNM [57, 67]. A two-fold increase of stillbirths was found among women with $\geq 2$ complications in the Gambia (47). Similarly, maternal obstetric complications have been shown to play a role in the underlying causes of neonatal deaths $(41,66)$. Therefore, early screening for poor obstetric conditions during ANC and appropriate management of intrapartum complications are crucial to ensure a reduction of NNM.

The current study did not establish any association between ANC and NNM, unlike a study in southern Ethiopia, where adequate ANC visits were associated with less NNM (28). Attending $\geq 4$ ANC sessions was protective, whereas an inadequate number of antenatal visits was associated with risk of neonatal mortality and adverse birth outcome (65). Possible explanations for non-association in our study were, firstly, that only a quarter (24\%) of women in Nepal received all seven components of ANC (67). The majority of Nepal public institutions lack basic ultrasonography and laboratory facilities (blood and urine testing) and most pregnant women only receive health education, iron supplementation, blood pressure measurements and anti-tetanus toxoid (67). Secondly, there is poor compliance by pregnant mothers with 
ANC advice (68). Hence, women with or without attending $\geq 4$ ANC sessions did not show any association with NNM.

With advancing maternal age, the prevalence of pre-existing conditions appear to increase and also the risk of caesarean birth, contributing to increased fetal risks (69). Advanced maternal age and age $<18$ or $>20$ was significantly associated with NNM $[15,27,38-39,57-58,62,69]$. Secondary analysis of the WHO multi-country survey on maternal and newborn health showed that advanced maternal age significantly increased the risk of stillbirths and perinatal deaths (69). No association, however, was established between maternal age and NNM in our study.

\section{Strengths and limitations}

Results of the current study are generalizable to births in government institutions in Nepal. To the best of our knowledge, this is the only study that explored factors that impact NNM in South Asia, using both pragmatic and management criteria. The study also had several limitations. The cross-sectional nature meant that causal associations could not be proved. Seventeen of the 44 neonates with conditions requiring admission to NICU were self-referred to private hospitals with unavailable data. Date of the last menstrual period was used to calculate gestational age, possibly introducing incorrect estimations due to recall bias.

\section{Recommendations}

Nulliparity and SMM should be considered high-risk obstetric conditions. Therefore, screening should be performed during ANC and, if indicated, referral should be made to hospitals with adequate facilities. Future studies should explore contributory factors to NNM in illiterate women and those with communication barriers, as well as quality of ANC. Evaluation of the risk of NNM is recommended in specific maternal populations, such as advanced aged women, and those with multiple pregnancies. Near misses are lives saved due to timely intervention, so future studies should standardize its definition.

\section{Conclusion}

Maternal determinants could result in NNM. Neonates of mothers with SMM are at increased risk of NNM; conversely, caesarean section, multiparity and secondary and tertiary education reduced likelihood of NNM. Although caesarean section was found to reduce odds of NNM, this association requires additional evidence and safer access to caesarean section. Referral hospitals should be prepared to offer adequate emergency maternal and neonatal care to reduce NNM.

\section{Abbreviations}

SDG: Sustainable Development Goal; NNM: neonatal near miss; WHO: World Health Organization; NICU: neonatal intensive care unit; MNM: maternal near miss; aOR: adjusted odds ratio; Cl: confidence interval; 
BMI: body mass index; APGAR: Appearance, Pulse, Grimace, Activity, and Respiration; ANC: antenatal care; SMM: severe maternal morbidity

\section{Declarations}

Ethics approval and consent to participate

Ethical approval was obtained from the Human Research Ethics Committee Universiti Sains Malaysia (USM/JEPeM/19060356) and Nepal Health Research Council (Reg. no. 336/2019). Hospital administration's written approval was taken before data collection. Written consent of participants was taken before interview. Parental consent was taken for women $>18$ years.

\section{Consent for publication}

Not applicable.

\section{Availability of data and materials}

All data are available within the manuscript.

\section{Competing interest}

The authors declare that they have no competing interests.

\section{Funding}

This research was funded by Universiti Sains Malaysia Graduate Development Incentive Grant 311/PPSP/4404848. The funder had no role in the study design, data collection and analysis, decision to publish, or preparation of the manuscript.

\section{Authors' contributions}

SR designed the study, involved in data collection, analysed data and prepared the manuscript. NMN and $\mathrm{NHNH}$ designed the study, involved in data analysis and critically revised subsequent drafts for valuable intellectual content. All authors read and approved the final manuscript.

\section{Acknowledgment}

The authors would like to acknowledge Koshi Hospital and all individuals who were directly and indirectly involved in this study. We would like to thank Scribendi Inc (www.scribendi.com) for English Language review.

\section{References}


1. Hug L, Alexander M, You D, Alkema L. National, regional, and global levels and trends in neonatal mortality between 1990 and 2017, with scenario-based projections to 2030: a systematic analysis. The Lancet Global health. 2019;7(6):e710-e20.

2. WHO. Newborns: reducing mortality 2018 [Available from: https://www.who.int/news-room/factsheets/detail/newborns-reducing-mortality.

3. WHO, UNICEF. Every newborn: an action plan to end preventable deaths. Geneva: World Health Organization. 2014.

4. Ministry of Health Nepal, New ERA, ICF. Nepal Demographic and Health Survey 2016. Kathmandu, Nepal: Ministry of Health, Nepal; 2017.

5. WHO. Beyond the numbers: reviewing maternal deaths and complications to make pregnancy safer: World Health Organization; 2004.

6. Nakimuli A, Mbalinda SN, Nabirye RC, Kakaire O, Nakubulwa S, Osinde MO, et al. Still births, neonatal deaths and neonatal near miss cases attributable to severe obstetric complications: a prospective cohort study in two referral hospitals in Uganda. BMC Pediatrics. 2015;15(1):1-8.

7. Tekelab T, Chojenta C, Smith R, Loxton D. Incidence and determinants of neonatal near miss in south Ethiopia: a prospective cohort study. BMC Pregnancy Childbirth. 2020;20(1):1-13.

8. Mathai M. Reviewing maternal deaths and complications to make pregnancy and childbirth safer. WHO Regional Health Forum. 2005;9(1):27-9.

9. Pattinson RC. Near miss audit in obstetrics. MRC Maternal and Infant Health Care Strategies Research Unit, University of Pretoria. 2009.

10. Pileggi C, Souza JP, Cecatti JG, Faúndes A. Neonatal near miss approach in the 2005 WHO Global Survey Brazil. J Pediatr (Rio J). 2010;86(1):21-6.

11. Souza JP, Gülmezoglu AM, Vogel J, Carroli G, Lumbiganon P, Qureshi Z, et al. Moving beyond essential interventions for reduction of maternal mortality (the WHO Multicountry Survey on Maternal and Newborn Health): a cross-sectional study. Lancet (London, England). 2013;381(9879):1747-55.

12. Souza JP, Gülmezoglu AM, Carroli G, Lumbiganon P, Qureshi Z, Group WR. The world health organization multicountry survey on maternal and newborn health: study protocol. BMC Health Serv Res. 2011;11(1):286.

13. Pileggi-Castro C, Camelo Jr J, Perdoná G, Mussi-Pinhata M, Cecatti J, Mori R, et al. Development of criteria for identifying neonatal near-miss cases: analysis of two WHO multicountry cross-sectional studies. BJOG : an international journal of obstetrics and gynaecology. 2014;121:110-8.

14. Santos JP, Cecatti JG, Serruya SJ, Almeida PV, Duran P, Mucio Bd, et al. Neonatal Near Miss: the need for a standard definition and appropriate criteria and the rationale for a prospective surveillance system. Clinics (Sao Paulo, Brazil). 2015;70(12):820-6.

15. Surve S, Chauhan S, Kulkarni R. Neonatal near miss review: Tracking its conceptual evolution and way forward. Current Pediatric Research. 2017.

16. Silva AAM, Leite AJM, Lamy ZC, Moreira MEL, Gurgel RQ, Cunha AJLA, et al. Neonatal near miss in the birth in Brazil survey. Cad Saude Publica. 2014;30(SUPPL1):S182-S91. 
17. de Lima THB, Katz L, Kassar SB, Amorim MM. Neonatal near miss determinants at a maternity hospital for high-risk pregnancy in Northeastern Brazil: a prospective study. BMC Pregnancy Childbirth. 2018 October 12;18(1):401.

18. Rana HB, Banjara MR, Joshi MP, Kurth AE, Castillo TP. Assessing maternal and neonatal near-miss reviews in rural Nepal: an implementation research study to inform scale-up. Acta paediatrica (Oslo, Norway : 1992). 2018;107(471):17-23.

19. Ninama NH, Shroff BD. Will outlining neonatal near miss events make a change? A hospital based case control study. Int J Community Med Public Health. 2019;6(10):4570.

20. Shroff BD, Ninama NH. A Call for Eminence Obstetrics Care by Way of "Neonatal Near Miss" Events (NNM): A Hospital-Based Case-Control Study. J Obstet Gynaecol India. 2019;69(1):50-5.

21. Government of Nepal, Ministry of Health and Population, Department of Health Services. Annual Report: Department of Health Services FY 2074/75 (2017/2018). Nepal; 2017/18.

22. Nardello DM, Guimarães AMD, Barreto IDC, Gurgel RQ, Ribeiro ERO, Gois CFL. Fetal and neonatal deaths of children of patients classified as near miss. Rev Bras Enferm. 2017;70(1):104-11.

23. Bushtyrev VA, Bushtyreva IO, Kuznetsova NB, Budnik ES. Audit of neonatal near miss: Possibilities of improving in perinatology polymorphisms. Obstet Gynecol. 2016;7:79-82.

24. Santos JP, Pileggi-Castro C, Camelo JS, Jr., Silva AA, Duran P, Serruya SJ, et al. Neonatal near miss: a systematic review. BMC Pregnancy Childbirth. 2015;15:320.

25. Kale PL, Jorge MHPM, Silva KS, Fonseca SC. Neonatal near miss and mortality: Factors associated with life-threatening conditions in newborns at six public maternity hospitals in Southeast Brazil. Cad Saude Publica. 2017;33(4).

26. Kale PL, Jorge MHPM, Laurenti R, Fonseca SC, Silva KS. Pragmatic criteria of the definition of neonatal near miss: a comparative study. Rev Saude Publica. 2017;51:111.

27. Lawn JE, Cousens S, Zupan J, Team LNSS. 4 million neonatal deaths: when? Where? Why? Lancet (London, England). 2005;365(9462):891-900.

28. Mersha A, Bante A, Shibiru S. Factors associated with neonatal near-miss in selected hospitals of Gamo and Gofa zones, southern Ethiopia: nested case-control study. BMC Pregnancy Childbirth. 2019;19(1):1-8.

29. Nugussie F, Alemayehu M, Mariam KG. A case-control study examining determinants of neonatal near-miss in public hospitals in Tigray Region, Northern Ethiopia. J Med Sci Tech. 2019;7(3):1-11.

30. Tura AK, Scherjon S, van Roosmalen J, Zwart J, Stekelenburg J, van den Akker T. Surviving mothers and lost babies-burden of stillbirths and neonatal deaths among women with maternal near miss in eastern Ethiopia: a prospective cohort study. J Glob Health. 2020;10(1).

31. Debelew GT, Afework MF, Yalew AW. Determinants and causes of neonatal mortality in Jimma zone, southwest Ethiopia: a multilevel analysis of prospective follow up study. PLoS One. 2014;9(9).

32. Kananura RM, Tetui M, Mutebi A, Bua JN, Waiswa P, Kiwanuka SN, et al. The neonatal mortality and its determinants in rural communities of Eastern Uganda. Reprod Health. 2016;13(1):13. 
33. Morrison J, Najman J, Williams G, Keeping J, Andersen M. Socio-economic status and pregnancy outcome. An Australian study. BJOG : an international journal of obstetrics and gynaecology. 1989;96(3):298-307.

34. Ike Elizabeth U, Modupe 00. Pattern of diseases and care outcomes of neonates admitted in special care baby unit of University College Hospital, Ibadan, Nigeria from 2007 to 2011. Journal of Nursing and Health Science. 2015;4(1):62-71.

35. Walker KF, Thornton JG. Advanced maternal age. Obstet Gynaecol Reprod Med. 2016;26(12):354-7.

36. Ziadeh SM. Maternal and perinatal outcome in nulliparous women aged 35 and older. Gynecol Obstet Invest. 2002;54(1):6-10.

37. Kahveci B, Melekoglu R, Evruke IC, Cetin C. The effect of advanced maternal age on perinatal outcomes in nulliparous singleton pregnancies. BMC Pregnancy Childbirth. 2018;18(1):343.

38. Ezra Y, McParland P, Farine D. High delivery intervention rates in nulliparous women over age 35 . Eur J Obstet Gynecol Reprod Biol. 1995;62(2):203-7.

39. Nisar YB, Dibley MJ. Determinants of neonatal mortality in Pakistan: secondary analysis of Pakistan Demographic and Health Survey 2006-07. BMC Public Health. 2014;14(1):663.

40. Gupta S, Yamada G, Mpembeni R, Frumence G, Callaghan-Koru JA, Stevenson R, et al. Factors associated with four or more antenatal care visits and its decline among pregnant women in Tanzania between 1999 and 2010. PLoS One. 2014;9(7):e101893.

41. Al Kibria GM, Khanam R, Mitra DK, Mahmud A, Begum N, Moin SMI, et al. Rates and determinants of neonatal mortality in two rural sub-districts of Sylhet, Bangladesh. PLoS One. 2018;13(11):e0206795.

42. Jonas H, Khalid N, Schwartz S. The relationship between Caesarean section and neonatal mortality in very-low-birthweight infants born in Washington State, USA. Paediatr Perinat Epidemiol. 1999;13(2):170-89.

43. Silva GA, Rosa KA, Saguier ESF, Henning E, Mucha F, Franco SC. A populational based study on the prevalence of neonatal near miss in a city located in the South of Brazil: prevalence and associated factors. Revista Brasileira de Saúde Materno Infantil. 2017;17(1):159-67.

44. Avenant T. Neonatal near miss: a measure of the quality of obstetric care. Best Pract Res Clin Obstet Gynaecol. 2009;23(3):369-74.

45. Ronsmans C, Cresswell JA, Goufodji S, Agbla S, Ganaba R, Assarag B, et al. Characteristics of neonatal near miss in hospitals in Benin, Burkina Faso and Morocco in 2012-2013. Trop Med Int Health. 2016;21(4):535-45.

46. Malloy $\mathrm{MH}$. Impact of cesarean section on neonatal mortality rates among very preterm infants in the United States, 2000-2003. Pediatrics. 2008;122(2):285-92.

47. Cham M, Sundby J, Vangen S. Fetal outcome in severe maternal morbidity: too many stillbirths. Acta Obstet Gynecol Scan. 2009;88(3):343-9.

48. World Health Organization. Appropriate technology for birth. Lancet (London, England). 1985;2:436-7. 
49. Norhayati MN, Hazlina NHN, Sulaiman Z, Azman MY. Severe maternal morbidity and near misses in tertiary hospitals, Kelantan, Malaysia: a cross-sectional study. BMC Public Health. 2016;16(1):229.

50. Zwart J, Richters J, Öry F, De Vries J, Bloemenkamp K, Van Roosmalen J. Severe maternal morbidity during pregnancy, delivery and puerperium in the Netherlands: a nationwide population-based study of 371000 pregnancies. BJOG : an international journal of obstetrics and gynaecology. 2008;115(7):842-50.

51. Villar J, Valladares E, Wojdyla D, Zavaleta N, Carroli G, Velazco A, et al. Caesarean delivery rates and pregnancy outcomes: the $2005 \mathrm{WHO}$ global survey on maternal and perinatal health in Latin America. Lancet (London, England). 2006;367(9525):1819-29.

52. Sobhy S, Arroyo-Manzano D, Murugesu N, Karthikeyan G, Kumar V, Kaur I, et al. Maternal and perinatal mortality and complications associated with caesarean section in low-income and middleincome countries: a systematic review and meta-analysis. Lancet (London, England). 2019;393(10184):1973-82.

53. Litorp $H$, Kidanto HL, Rööst M, Abeid M, Nyström L, Essén B. Maternal near-miss and death and their association with caesarean section complications: a cross-sectional study at a university hospital and a regional hospital in Tanzania. BMC Pregnancy Childbirth. 2014;14(1):244.

54. Anggondowati T, El-Mohandes AA, Qomariyah SN, Kiely M, Ryon JJ, Gipson RF, et al. Maternal characteristics and obstetrical complications impact neonatal outcomes in Indonesia: a prospective study. BMC Pregnancy Childbirth. 2017;17(1):100.

55. Ezeh OK, Agho KE, Dibley MJ, Hall J, Page AN. Determinants of neonatal mortality in Nigeria: evidence from the 2008 demographic and health survey. BMC Public Health. 2014;14(1):521.

56. Adewuyi E, Zhao Y, Lamichhane R. Socioeconomic, bio-demographic and health/behavioral determinants of neonatal mortality in Nigeria: a multilevel analysis of 2013 demographic and health survey. Int J Contemp Pediatrics. 2016;3(2):311-23.

57. Bayrampour $\mathrm{H}$, Heaman M. Advanced maternal age and the risk of cesarean birth: a systematic review. Birth. 2010;37(3):219-26.

58. Souza JP, Cecatti JG, Faundes A, Morais SS, Villar J, Carroli G, et al. Maternal near miss and maternal death in the World Health Organization's 2005 global survey on maternal and perinatal health. Bulletin of the World Health Organization. 2010;88:113-9.

59. Rutstein SO. Effects of preceding birth intervals on neonatal, infant and under-five years mortality and nutritional status in developing countries: evidence from the demographic and health surveys. Obstet Gynecol Int J. 2005;89:S7-S24.

60. Morais LR, Patz BC, Campanharo FF, Dualib PM, Sun SY, Mattar R. Neonatal Near Miss among Newborns of Women with Type 1 Diabetes Mellitus. Obstet Gynecol Int. 2019:8594158-.

61. Souza J, Cecatti J, Parpinelli M, Sousa M, Lago T, Pacagnella R, et al. Maternal morbidity and near miss in the community: findings from the 2006 Brazilian demographic health survey. BJOG : an international journal of obstetrics and gynaecology. 2010;117(13):1586-92. 
62. Zanardi DM, Parpinelli MA, Haddad SM, Costa ML, Sousa MH, Leite DF, et al. Adverse perinatal outcomes are associated with severe maternal morbidity and mortality: evidence from a national multicentre cross-sectional study. Arch Obstet Gynaecol. 2019;299(3):645-54.

63. Oliveira LC, Costa AAR. Fetal and neonatal deaths among maternal near miss cases. Rev Assoc Med Bras. 2013;59(5):487-94.

64. Osmundson SS, Gould JB, Butwick AJ, Yeaton-Massey A, El-Sayed YY. Labor outcome at extremely advanced maternal age. Am J Obstet Gynecol. 2016;214(3):362. e1-. e7.

65. Tsegaye B, Kassa A. Prevalence of adverse birth outcome and associated factors among women who delivered in Hawassa town governmental health institutions, south Ethiopia, in 2017. Reprod Health. 2018;15(1):193.

66. Batieha AM, Khader YS, Berdzuli N, Chua-Oon C, Badran EF, Al-sheyab NA, et al. Level, causes and risk factors of neonatal mortality, in Jordan: results of a national prospective study. Matern Child Health J. 2016;20(5):1061-71.

67. Joshi C, Torvaldsen S, Hodgson R, Hayen A. Factors associated with the use and quality of antenatal care in Nepal: a population-based study using the demographic and health survey data. BMC Pregnancy Childbirth. 2014 2014/03/03;14(1):94.

68. Paz-Zulueta M, Llorca J, Sarabia-Lavín R, Bolumar F, Rioja L, Delgado A, et al. The role of prenatal care and social risk factors in the relationship between immigrant status and neonatal morbidity: a retrospective cohort study. PLoS One. 2015;10(3):e0120765.

69. Laopaiboon M, Lumbiganon P, Intarut N, Mori R, Ganchimeg T, Vogel J, et al. Advanced maternal age and pregnancy outcomes: a multicountry assessment. BJOG : an international journal of obstetrics and gynaecology. 2014;121:49-56. 